J. Clin. Chem. Clin. Biochem.

Vol. 19, 1981, pp. 919-924

\title{
An Improved Method for the Determination of the Plasma Volume with Evans Blue
}

\author{
By J. Zweens and Henny Frankena \\ Department of Physiology, University of Groningen, The Netherlands
}

(Received September 9, 1980/January 13, 1981)

Summary: A new method for the spectrophotometric determination of Evans Blue in plasma is presented. The method is based on the precipitation of the non-albumin fraction of the plasma proteins with polyethylene glycol, in order to eliminate the variable background absorption of plasma at the wavelength of maximum absorbance of Evans Blue. The accuracy and precision of the method is excellent: at an Evans Blue concentration in plasma of $5 \mathrm{mg} \cdot \mathrm{I}^{-1}$ the coefficient of variation of the method is $<1 \%$. Five different procedures currently in use for the calculation of the plasma volume from the amount of indicator injected and the concentration at zero time $\left(c_{0}\right)$ were compared. Extrapolation to zero time of the early part (10 to $60 \mathrm{~min})$ of the log concentration $v s$ time curve turned out to be the best method for the calculation of $c_{0}$, and hence yields the best estimate of the plasma volume.

\section{Eine verbesserte Methode für die Bestimmung des Plasmavolumens mit Evans Blue}

Zusammenfassung: Eine neue Methode für die spektrophotometrische Bestimmung von Evans Blue wird beschrieben. Sie beruht auf der Fällung der Nicht-Albumin-Fraktion der Plasmaproteine mit Polyethylenglycol, um die variierende Untergrundabsorption von Plasma bei der Wellenlänge des Absorptionsmaximums von Evans Blue zu eliminieren. Richtigkeit und Genauigkeit der Methode sind hervorragend: bei einer Evans Blue-Konzentration von $5 \mathrm{mg} / 1$ Plasma ist der Variationskoeffizient der Methode $<1 \%$. Fünf verschiedene Verfahren, die gegenwärtig zur Ermittlung des Plasmavolumens aus der Menge an injiziertem Indikator und der Konzentration zum Zeitpunkt $t=0\left(c_{0}\right)$ Verwendung finden, wurden verglichen. Extrapolation des frühen Teils (10-60 $\mathrm{min})$ der log Konzentration gegen Zeit-Kurve auf die Zeit $\mathrm{t}=0$ erwies sich als die beste Methode für die Ermittlung von $c_{0}$ und ergibt deshalb den besten Wert für das Plasmavolumen.

\section{Introduction}

The plasma volume can be measured by indicator dilution, using albumin labelled with Evans Blue (T-1824), or with radio-iodine. All methods described up to now for the determination of Evans Blue in plasma (1) are based on one of the following principles:

1. spectrophotometry against a plasma blank;

2. two-wavelength spectrophotometry;

3. spectrophotometry after extraction of the dye.

Because of the many difficulties encountered in the use of these methods, Evans Blue has almost gone out of use. In this investigation we have tried to improve the determination. Polson \& Ruiz-Bravo (2) reported the use of polyethylene glycol in the fractionation of plasma proteins. Unlike the majority of the protein fractionation agents, polyethylene glycol separates components from a mixture by a volume exclusion mechanism. The easy and accurate method for the determination of Evans Blue in plasma described in this paper is based on the precipitation with polyethylene glycol of all proteins except albumin. It can be used in plasmas of widely divergent opacity and in plasmas with some degree of haemolysis.

Furthermore, using dogs, we have performed a series of experiments to compare the different methods in use for the calculation of the plasma volume with the method for the calculation of an indicator distribution volume according to Meier \& Zierler (3). This latter method needs a rather large number of samples and a laborious procedure to calculate the plasma volume, but it gives the most accurate results and hence is the best reference method. 


\section{Methods and Experiments}

\section{Determination of the plasma Evans Blue concentration after} treatment of the plasma with polyethylene glycol

The optimum polyethylene glycol concentration (average relative molecular mass 4000 ) for the precipitation of the non-albumin fraction of the plasma proteins was determined in a preliminary experiment. Figure 1 shows that after the addition of one part polyethylene glycol $240 \mathrm{~g} \cdot \Gamma^{-1}$ to one part of human plasma, the albumin fraction remains dissolved but the other protein fractions are precipitated almost completely, whereas at higher polyethylene glycol concentrations part of the albumin fraction is also precipitated. The precipitation was complete within $10 \mathrm{~min}$. The same results were obtained in dog plasma. On the basis of these findings the following method was adopted.

1. Add 1 part polyethylene glycol $240 \mathrm{~g} \cdot \Gamma^{-1}$ to 1 part plasma.

2. Allow to stand for $10 \mathrm{~min}$.

3. Spin at $7000 \mathrm{~g}$ for $10 \mathrm{~min}$.

4. Read the absorbance of the supernatant against a similarly treated plasma blank at the wavelength of maximum absorbance (man, $\lambda=620 \mathrm{~nm}$; dog, $\lambda=627 \mathrm{~nm}$ ) and convert the measured absorbances into concentrations with the aid of a calibration line, made by mixing different volumes of a $5 \mathrm{~g} \cdot \mathrm{r}^{-1}$ Evans Blue solution in $9 \mathrm{~g} \cdot \mathrm{I}^{-1} \mathrm{NaCl}$ with plasma.

At the wavelengths used the absorbance of Evans Blue obeys Lambert-Beer's law at least from 1.5 to $25 \mathrm{mg} \cdot 1^{-1} \quad(r=0.9999)$ with an absorptivity of $0.0391 \cdot \mathrm{mg}^{-1} \cdot \mathrm{cm}^{-1}$ in human and $\mathrm{dog}$ plasma.

\section{Other methods for the determination of the plasma Evans Blue concentration}

In a number of experiments the plasma Evans Blue concentration was also determined with a signle-wavelength method (4), a twowavelength method (5) and an acetone extraction method (6).

\section{Experiments in vitro}

To determine whether treatment with polyethylene glycol sufficiently reduces the background absorption caused by opacity and slight haemolysis, the absorbance at $\lambda=620 \mathrm{~nm}\left(A_{620}\right)$ was measured in a series of 68 human plasma samples (normal, lipaemic, haemolytic with a haemoglobin concentration up to $\left.1.2 \mathrm{~g} \cdot \mathrm{I}^{-1}\right)$ and at $\lambda=627 \mathrm{~nm}\left(A_{627}\right)$ in a series of 26 dog plasma samples, before and after treatment with polyethylene glycol.

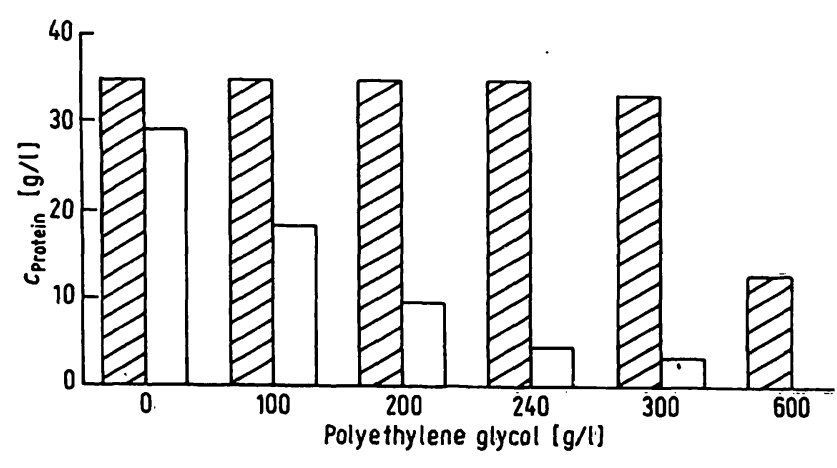

Fig. 1. Effect of polyethylene glycol on the solubility of the plasma proteins. Equal parts of polyethylene glycol solutions (concentrations given under each column) and plasma were mixed at room temperature. The amount of albumin (hatched columns) and non-albumin fraction (white columns) remaining in solution is given in $\mathrm{g} \cdot \mathrm{I}^{-1}$ plasma.
To test whether the plasma protein concentration influences the absorbance of Evans Blue after polyethylene glycol treatment, human and dog plasma was diluted with $\mathrm{NaCl} 9 \mathrm{~g} \cdot \mathrm{I}^{-1}$ to get protein concentrations from 20 to $70 \mathrm{~g} \cdot \mathrm{l}^{-1}$. To $1.5 \mathrm{ml}$ of these solutions $3 \mu$ l Evans Blue solution $5 \mathrm{~g} \cdot \mathrm{I}^{-1}$ was added and $A_{620}$ and $A_{627}$ measured after treatment with polyethylene glycol. To study the influence of haemoglobin on the absorbance of Evans Blue after treatment with polyethylene glycol, a haemolysate was added to dog plasma to obtain haemoglobin concentrations from 0 to $0.2 \mathrm{~g} \cdot 1^{-1}$. To $1.5 \mathrm{ml}$ of these solutions $3 \mu \mathrm{l}$ Evans Blue solution $5 \mathrm{~g} \cdot \mathrm{l}^{-1}$ was added and $A_{627}$ measured after treatment with polyethylene glycol.

To determine the precision of the method, Evans Blue was added to plasma to a concentration of $2.5,5,7.5$ and $10 \mathrm{~g} \cdot \mathrm{l}^{-1}$ and 20 replicate determinations were run on these samples. To determine the accuracy of the polyethylene glycol method in comparison with other methods, Evans Blue was added to different plasma samples to a concentration of $5 \mathrm{mg} \cdot \mathrm{r}^{-1}$ and the Evans Blue concentrations determined with the single-wavelength method, the two-wavelength method, the acetone extraction method and the polyethylene glycol method.

\section{Experiments in vivo}

The plasma volume $(V P)$ was determined in 10 male mongrel dogs $(23-33 \mathrm{~kg})$ with permanent vascular catheters (7). All animals were in good health with body temperatures between 38.5 and $38.9^{\circ} \mathrm{C}$; they were fed with standard pellets (Hope Farms, Woerden, The Netherlands) with the addition of ox tripe, and had free access to water. The dog, lying quietly in a basket, was given $1 \mathrm{ml}$ per $\mathrm{kg}$ body mass of a solution containing $0.4 \mathrm{~g} \cdot \mathrm{r}^{-1}$ Evans Blue in $9 \mathrm{~g} \cdot \mathrm{l}^{-1} \mathrm{NaCl}$ as a single injection through the catheter in the pulmonary artery. The exact amount of Evans Blue administered was calculated from the density and the mass of the solution injected, determined by weighing the syringe to the nearest $0.005 \mathrm{~g}$ before and after - the injection. Blood samples were taken before and $1,2,5,7.5$, $10,12.5,15,20,30,40,50,60,70,80,90,105,120,135,150$ 180 and $240 \mathrm{~min}$ after the injection, zero time being chosen halfway between the start and the end of the injection which took about $20 \mathrm{~s}$. Blood loss through sampling was compensated for by intravenous administration of $9 \mathrm{~g} \cdot \mathrm{l}^{-1} \mathrm{NaCl}$ solution.

$V^{P}$ was calculated in two different ways. Starting from the relation volume $=$ flow $X$ transit time, in which the flow is represented by the clearance of the indicator from the blood stream, Meier \& Zierler (3) showed that

$$
V=m^{i} \cdot \frac{f_{0} t \cdot c_{t} d t}{\left(\int_{0} c_{t} d t\right)^{2}}
$$

in which $m^{i}$ denotes the amount of indicator injected and $c_{t}$ the plasma indicator concentration at time $t$. The concentration $c_{t}$ is obtained from the plasma indicator concentration $v s$ time curve which is described over the pcriod 0 to $60 \mathrm{~min}$ by two or three exponential functions. In addition, $V^{p}$ was calculated using the equation

$$
V=\frac{m^{i}}{c_{0}}
$$

The indicator concentration at time zero $\left(c_{0}\right)$ was obtained in 5 different ways.

A. $c_{0}=1.015 c_{10}, 1.015$ being the correction factor for the indicator loss during the first $10 \mathrm{~min}(8,9)$.

B. $c_{0}=\left(c_{10}+c_{20}\right) / 2(10,11)$.

C. Linear extrapolation of the early disappearance curve, i.e. the concentration vs time curve from 10 to $60 \mathrm{~min}(12,13)$.

D. Semilogarithmic extrapolation of the early disappearance curve (14).

E. Semilogarithmic extrapolation of the late disappearance curve, i.e. the concentration vs time curve from 120 to $240 \mathrm{~min}$ (15). 


\section{Results}

Treatment with polyethylene glycol reduced $A_{620}$ from $0.285 \pm 0.153$ to $0.024 \pm 0.004$ in the Evans Blue-free human plasma samples and $A_{627}$ from $0.158 \pm 0.104$ to $0.014 \pm 0.003$ in dog plasma. In human and dog plasmas with protein concentrations from 20 to $70 \mathrm{~g} \cdot \mathrm{l}^{-1}$ the absorbances of $10 \mathrm{mg} \cdot 1^{-1}$ Evans Blue were equal, showing that the absorbance of Evans Blue is not influenced by the plasma protein content. Spectrophotometric assay of haemolytic plasmạ samples, containing no added Evans Blue, against a non-haemolytic plasma blank showed that treatment with polyethylene glycol strongly diminishes the haemoglobin-caused absorbance and at $c_{\mathrm{Hb}}<0.8 \mathrm{~g} \cdot 1^{-1}$, in fact eliminates it. Table 1 shows that the presence of haemolysis does not influence the recovery of Evans Blue when each sample is read against its own polyethylene glycol-treated plasma blank. When each sample is read against the non-haemolytic polyethylene glycol-treated plasma blank, the influence of haemolysis can be neglected up to $c_{\mathrm{Hb}}=0.8 \mathrm{~g} \cdot \mathrm{1}^{-1}$, but at concentrations above $1.2 \mathrm{~g} \cdot \mathrm{l}^{-1}$ its effect becomes appreciable. In table 2 the data on the accuracy and the precision of the method at different concentration levels are given. The recovery of added Evans Blue is excellent, and at a concentration of 2.5 $\mathrm{mg} \cdot \mathrm{l}^{-1}$ and upwards the coefficient of variation (C.V.) of the method is $<1 \%$. Data on the accuracy and precision of the method in comparison with other methods are given in table 3. Figure 2 shows a typical early arterial disappearance curve of Evans Blue in a dog as determined with the four different measuring methods.

Tab. 1. Recovery of Evans Blue added to plasma $\left(10 \mathrm{mg} \cdot \mathrm{l}^{-1}\right)$ with increasing degree of haemolysis after treatment with polyethylene glycol. Number of experiments 4; Evans Blue concentration \pm s.d.

\begin{tabular}{lll}
\hline $\begin{array}{l}c_{\mathrm{Hb}} \\
\left(\mathrm{g} \cdot \mathrm{I}^{-1}\right)\end{array}$ & $\begin{array}{l}\text { Evans Blue recovered } \\
\left.\text { read against own } \cdot \mathrm{I}^{-1}\right) \\
\text { haemolytic } \\
\text { plasma blank }\end{array}$ & $\begin{array}{l}\text { read against non- } \\
\text { haemolytic } \\
\text { plasma blank }\end{array}$ \\
\hline 0 & $10.01 \pm 0.06$ & $10.02 \pm 0.05$ \\
0.4 & $9.96 \pm 0.08$ & $10.06 \pm 0.09$ \\
0.8 & $9.92 \pm 0.07$ & $10.11 \pm 0.07$ \\
1.2 & $10.01 \pm 0.05$ & $10.23 \pm 0.08$ \\
1.6 & $10.07 \pm 0.06$ & $10.46 \pm 0.09$ \\
2.0 & $10.04 \pm 0.08$ & $10.63 \pm 0.07$ \\
\hline
\end{tabular}

Tab. 2. Recovery and precision of different concentration levels of Evans Blue in plasma after polyethylene glycol treatment. Evans Blue concentrations \pm s.d.

\begin{tabular}{lll}
\hline $\begin{array}{l}\text { Evans Blue added } \\
\left(\mathrm{mg} \cdot \mathrm{I}^{1}\right)\end{array}$ & $\begin{array}{l}\text { Evans Blue recovered } \\
\left(\mathrm{mg} \cdot \mathrm{I}^{-1}\right)\end{array}$ & $\begin{array}{l}\text { Number of } \\
\text { experiments }\end{array}$ \\
\hline 2.5 & $2.503 \pm 0.025$ & 20 \\
5.0 & $5.007 \pm 0.024$ & 20 \\
7.5 & $7.504 \pm 0.028$ & 20 \\
10.0 & $9.997 \pm 0.027$ & 20 \\
\hline
\end{tabular}

Tab. 3. Accuracy and precision of the polyethylene glycol method for the determination of Evans Blue in plasma in comparison with other methods. $n=10$ in each series.

\begin{tabular}{lll}
\hline Method & $\begin{array}{l}\text { Evans Blue } \\
\text { added } \\
\left(\mathrm{mg} \cdot \mathrm{l}^{-1}\right)\end{array}$ & $\begin{array}{l}\text { Evans Blue } \\
\text { recovered } \\
\left(\mathrm{mg} \cdot \mathrm{I}^{-1}\right)\end{array}$ \\
\hline $\begin{array}{l}\text { Single wavelength } \\
\text { Two wavelength }\end{array}$ & 5.000 & $6.480 \pm 1.957$ \\
Acetone extraction & 5.000 & $4.894 \pm 0.382$ \\
Polyethylene glycol & 5.000 & $5.092 \pm 0.241$ \\
\hline
\end{tabular}

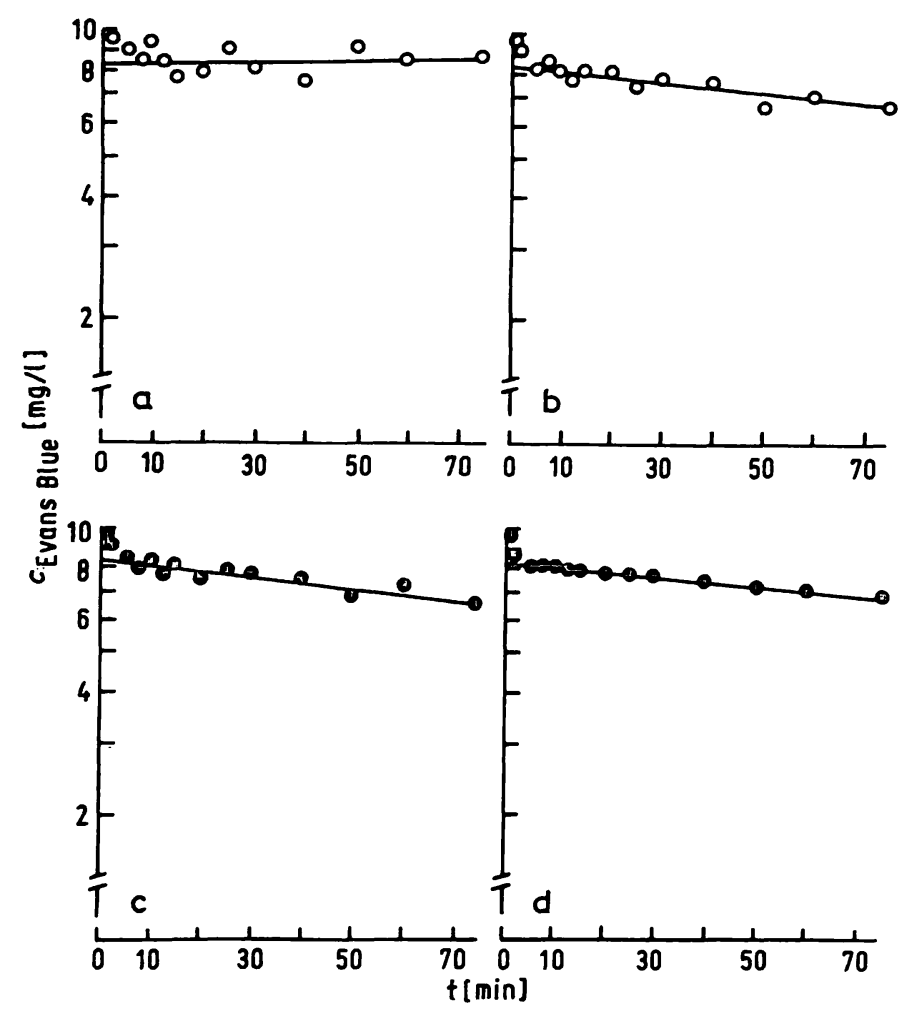

Fig. 2. Evans Blue concentration $\nu s$ time curve in plasma after intravenous injection in a dog. The Evans Blue concentration of the plasma samples was determined with four different methods. The Evans Blue concentration in plasma is plotted logarithmically against time. The regression line is calculated over the period 10 to $60 \mathrm{~min}$.

Methcds: a Single wavelength

b Two wavelengths

c Acetone extraction

d Polyethylene glycol precipitation

The variation around the line of best fit is inversely proportional to the accuracy and precision of the methods. Table 4 presents the values for $V^{p}$ with their $95 \%$ confidence interval in dogs, calculated using Eq. 2 for which $c_{0}$ was obtained by semilogarithmic extrapolation to zero time of the plasma concentration $v s$ time curve over the period from 10 to $60 \mathrm{~min}$. The plasma Evans Blue concentration was determined by the four different methods. Table 5 presents the values for $V^{p}$ calculated with Eq. 2 and the plasma Evans Blue concentration determined with the polyethylene glycol method. For the substitu- 
Tab. 4. Plasma volume $\left(V^{p}\right)$ of conscious dogs as determined with different methods within the same experiment.

\begin{tabular}{|c|c|c|c|c|}
\hline & \multicolumn{4}{|c|}{ Plasma volume $\left(\mathrm{ml} \cdot \mathrm{kg}^{-1}\right)$} \\
\hline & $\begin{array}{l}\text { Method } \\
1\end{array}$ & 2 & 3 & 4 \\
\hline \multicolumn{5}{|c|}{ Exp. } \\
\hline 1 & $94 \pm 31$ & $77 \pm 6$ & $78 \pm 5$ & $78 \pm 1$ \\
\hline 2 & $48 \pm 20$ & $53 \pm 4$ & $56 \pm 4$ & $59 \pm 1$ \\
\hline 3 & $63 \pm 3$ & $62 \pm 2$ & $66 \pm 3$ & $63 \pm 1$ \\
\hline 4 & $54 \pm 6$ & $54 \pm 4$ & & $56 \pm 0.5$ \\
\hline 5 & $90 \pm 17$ & $49 \pm 7$ & $50 \pm 3$ & $48 \pm 1$ \\
\hline 6 & $57 \pm 4$ & $57 \pm 3$ & $59 \pm 3$ & $58 \pm 1$ \\
\hline 7 & $130 \pm 51$ & $53 \pm 6$ & $57 \pm 2$ & $59 \pm 0.5$ \\
\hline 8 & $60 \pm 9$ & $59 \pm 5$ & & $55 \pm 1$ \\
\hline 9 & $57 \pm 4$ & $62 \pm 2$ & & $62 \pm 0.5$ \\
\hline 10 & $33 \pm 4$ & $41 \pm 3$ & & $40 \pm 0.5$ \\
\hline
\end{tabular}

$V^{P}$ was calculated from the amount of Evans Blue injected $\left(m^{i}\right)$ and the Evans Blue concentration at zero time obtained by extrapolation to zero time of the log indicator $v s$ time curve over the period 10 to $60 \mathrm{~min}$.

1. single wavelength method

2. two wavelength method

3. acetone extraction

4. polyethylene glycol method

$V^{p}$ per unit of body mass $\pm 95 \%$ confidence interval is given in $\mathrm{ml} \cdot \mathrm{kg}^{-1}$.

Tab. 5. Plasma volume $\left(V^{P}\right)$ in conscious dogs calculated with Eq. 2 from the amount of Evans Blue injected and the Evans Blue concentration at zero time $\left(c_{0}\right)$, the latter being obtained in different ways.

\begin{tabular}{|c|c|c|c|c|c|}
\hline \multirow[b]{2}{*}{ Exp. } & \multicolumn{2}{|c|}{$\frac{V^{p} \text { (Eq. 2) }}{V^{p} \text { (Eq. 1) }} \cdot 100$} & \multirow[t]{2}{*}{3} & \multirow[t]{2}{*}{4} & \multirow[t]{2}{*}{5} \\
\hline & & & & & \\
\hline $\begin{array}{r}1 \\
2 \\
3 \\
4 \\
5 \\
6 \\
7 \\
8 \\
9 \\
10\end{array}$ & $\begin{array}{r}100.626 \\
94.791 \\
101.692 \\
100.771 \\
101.353 \\
102.041 \\
99.857 \\
100.278 \\
100.994 \\
99.518\end{array}$ & $\begin{array}{l}103.448 \\
100.595 \\
103.961 \\
102.478 \\
105.667 \\
105.401 \\
103.170 \\
102.871 \\
103.755 \\
103.612\end{array}$ & $\begin{array}{r}100.649 \\
101.095 \\
101.367 \\
99.272 \\
103.217 \\
100.450 \\
102.280 \\
100.669 \\
100.758 \\
103.392\end{array}$ & $\begin{array}{r}100.372 \\
100.930 \\
100.443 \\
99.674 \\
100.135 \\
99.803 \\
100.000 \\
100.151 \\
100.120 \\
100.000\end{array}$ & $\begin{array}{l}115.101 \\
110.532 \\
118.344 \\
109.390 \\
103.239 \\
121.038 \\
113.190 \\
105.533 \\
105.945 \\
116.580\end{array}$ \\
\hline $\begin{array}{l}\text { Mean } \\
\pm S D\end{array}$ & $\begin{array}{l}100.192 \\
\pm 2.053\end{array}$ & $\begin{array}{r}103.496 \\
\pm 1.437\end{array}$ & $\begin{array}{r}101.315 \\
\pm 1.291\end{array}$ & $\begin{array}{r}100.163 \\
\pm 0.355\end{array}$ & $\begin{array}{r}111.889 \\
\pm 5.944\end{array}$ \\
\hline
\end{tabular}

- The Evans Blue concentration was determiined with the polyethylene glycol method. $V^{P}$ calculated with Eq. 2 is given as a percentage of $V^{p}$ calculated with $\mathrm{Eq} .1$ which was used as a reference method (see text).

1. $c_{0}=1.015 \cdot c_{10}$

2. $c_{0}=\left(c_{10}+c_{20}\right) / 2$

3. $c_{0}$ obtained by linear extrapolation of the concentration $\nu$ s time curve from $10-60 \mathrm{~min}$

4. $c_{0}$ obtained by semilogarithmic extrapolation of the concentration $v s$ time curve from $10-60 \mathrm{~min}$

5. $c_{0}$ obtained by semilogarithmic extrapolation of the concentration $v s$ time curve from 120-240 min. tion in Eq. 2, $c_{0}$ was calculated in five different ways and the resulting $V^{p}$ expressed as a percentage of $V^{p}$ calculated with Eq. 1 in order to allow better mutual comparison.

\section{Discussion}

Since its introduction as an agent for fractionating proteins (16), polyethylene glycol has also come into use for the fractionation of serum proteins (17). Fractional precipitation of proteins with polyethylene glycol involves insolubilization of the components by superconcentrating them in the inter-polyethylene glycol spaces by volume exclusion, and does not involve any chemical reaction by direct linkage or dehydration of the proteins. It does not detach Evans Blue from albumin which is shown by the fact that addition of one part polyethylene glycol $240 \mathrm{~g} \cdot 1^{-1}$ to one part plasma does not lower the wavelength of maximum absorbance (the wavelength of maximum absorbance of Evans Blue in water and in polyethylene glycol $120 \mathrm{~g} \cdot 1^{-1}$ is 610 $\mathrm{nm})$. Although most experimental work on polyethylene glycol fractionation was done with polyethylene glycol 6000 , we preferred to use polyethylene glycol 4000 as it is less viscous in solutions of the same concentration $(w / v)$. This is justified by the results shown in figure 1 ; one to one addition of $240 \mathrm{~g} \cdot \mathrm{l}^{-1}$ polyethylene glycol 4000 to human and dog plasma precipitates more than $90 \%$ of the non-albumin fraction of the proteins, leaving the albumin fraction in solution.

As the opacity of the plasma is predominantly linked to the non-albumin fraction of the plasma proteins, precipitation of the latter was expected to be effective in eliminating the absorbance of plasma at the wavelength of maximum absorbance of Evans Blue. Our results show that in human and dog plasma $A_{620}$ and $A_{627}$ are indeed greatly reduced and their variability virtually eliminated after treatment with polyethylene glycol. Moreover, they show that the polyethylene glycol method is not hampered by slight haemolysis of the plasmas (tab. 1).

The data in table 2 show that the polyethylene glycol method is very accurate and precise; its C.V. is better than that of the radio-iodinated serum albumin determination (13). Data on the accuracy and precision of the polyethylene glycol method in comparison with other methods for the determination of Evans Blue (tab. 3) show that the single-wavelength method does not come up to the requirements of accuracy and precision, while both the two-wavelength method and the acetone extraction method, though sufficiently accurate, do lack in precision. The polyethylene glycol method outranks the other methods in accuracy and precision, and yet competes in easiness with the single-wavelength method. The shortcomings of the single-wavelength method, and to a lesser extent of the two-wavelength 
method, must be ascribed to the variation in plasma background between different plasma samples even within one and the same specimen over a short period of time. In blood samples from three different dogs taken every $10 \mathrm{~min}$ for $2 \mathrm{~h}, A_{627}$ of the plasmas was found to vary at random between $0.044-0.169$, $0.068-0.257$ and $0.039-0.214$, respectively. As for the acetone extraction method, Tornberg (6) reported a recovery of Evans Blue of $5.10 \pm 0.05 \mathrm{mg} \cdot 1^{-1}$ at the level of $5 \mathrm{mg} \cdot 1^{-1}$, but in our experience as in that of others (1) the C.V. of this method is well over $2 \%$. Yet, the acetone extraction method remains the method of choice where strongly haemolytic plasmas are concerned. The scatter of the concentrations around the disappearance curves (fig. 2) and the $95 \%$ confidence interval of the values for $V^{p}$ (tab. 4) show that the four different methods yield an estimate of $V^{p}$ in accordance with their accuracy and precision. The polyethylene glycol method yields an estimate 3 to 4 times better than the acetone extraction method and the two-wavelength method, which in turn yield a much better estimate than the single-wavelength method.

To our knowledge Eq. 1 has not been used before for calculating the plasma volume. In the initial period after the injection of Evans Blue (0-60 min) the re-entry of Evans Blue labelled albumin is negligible and the Evans Blue disappearance curve is determined by mixing with the plasma and by the transcapillary escape rate. When mixing is complete (after about $10 \mathrm{~min}$ ), Evans Blue disappears from the plasma in a first-order fashion and the concentration $v s$ time curve is mono-exponential, provided that no changes in the transcapillary escape of albumin occur. Eq. 1 takes into account the whole disappearance curve and, unlike the extrapolation procedures used to obtain $c_{0}$ for Eq. 2, does not neglect the transcapillary loss in excess of the first-order elimination during the mixing time. Therefore, Eq. 1 was chosen as a reference for the calculation of $V^{p}$ from Eq. 2.

From table 5 it is obvious that the error resulting from semilogarithmic extrapolation of the early disappearance curve (procedure $D$ ) is negligible when the boundary conditions for the use of Eq. 2 (high distribution velocity of the indicator in comparison with its clearance and clearance small in comparison with its distribution volume) are fulfilled. When they are not met, the use of Eq. 1 is preferable (18). The error resulting from linear extrapolation of the early disappearance curve (procedure $\mathrm{C}$ ) is not negligible but still small, because over a short period of time the disappearance curve can reasonably be approximated by a linear function. The error resulting from semilogarithmic extrapolation of the late disappearance curve (procedure E) is considerable. The early disappearance curve is virtually uninfluenced by re-entry of Evans Blue into the vascular compartment, but re-entry becomes gradually more prominent. The slope of the disappearance curve flattens and $c_{0}$ obtained by extrapolation strongly underestimates its true value.

The error in the single-sample or two-sample procedures can be significant when the transcapillary loss is faster than average or when the mixing time is prolonged. Both conditions, that are shown by the early disappearance curve, are not recognized when a single- or two-sample procedure is used. Moreover, the two-sample procedure systematically overestimates $V^{p}$ as the loss of indicator is not corrected for.

The present investigation has shown that the Evans Blue concentration in plasma can reliably be determined by the polyethylene glycol method. This makes it possible to determine $V^{p}$ with an indicator which upon injection into the bloodstream binds exclusively to the patient's own albumin and eliminates the necessity of using radioisotope-labelled foreign albumin which is generally less accurately determined, is more expensive and has to be obtained from hepatitis B antigen negative donors. With a view to accuracy and precision, preference should be given to the multiple sampling technique and the calculation of $c_{0}$ using Eq. 1, or using Eq. 2. with $c_{0}$ obtained by semilogarithmic extrapolation to zero time of the early disappearance curve, which usually can be reliably carried out with 4 samples taken between 20 and 50 min after injection. When the multiple sampling technique is not feasible the single- or two-sample technique with appropriate correction for the loss of indicator offers a reasonable alternative, provided that transcapillary escape rate and mixing time are not grossly abnormal.

\section{References}

1. Henry, R. J. (1964), Clinical Chemistry, principles and techniques, 2nd. ed., Harper and Row, N.Y.

2. Polson, A. \& Ruiz-Bravo, C. (1972), Vox Sang. 23, 107-118.

3. Meier, P. \& Zierler, K. L. (1954), J. Appl. Physiol. 6, $731-744$.

4. Gregersen, M. J. (1944), J. Lab. Clin. Med. 26, 1266-1286.

5. Hamilton, L. H. (1958), J. Lab. Clin. Med. 52, 762-767.

6. Tornberg, A. (1958), Acta Med. Scand. 161, 69-77.

7. Zweens, J. \& Schiphof, P. (1976), Pflügers Arch. 362, 201-202.

8. International Committee for Standardization in Haematology. Standard techniques for the measurement of red-cell and plasma volume (1973). Brit. J. Haematol. 25, 801-814.

9. Noble, R. P. \& Gregersen, M. J. (1946), J. Clin. Invest. 25, $158-171$.

10. Baker, C. H. \& Remington, J. W. (1960), Amer. J. Physiol. 198, 906-910.

11. Campbell, T. J., Frohman, B. \& Reeve, E. B. (1958), J. Lab. Clin. Med. 52, 768-777.

12. Birkeland, S. (1965), J. Oslo City Hospital 15, 5-76. 
13. Harrison, M. H. \& Edwards, R. J. (1976), Aviat. Space Environ. Med. 47, 1038-1045.

14. Chinard, F. P. (1951), Methods Med. Res. 4, 38-48.

15. Kraan, W. J., Huisman, G. H. \& Velthuizen, J. (1978), Eur. J. Appl. Physiol. 38, 197-206.

16. Polson, A., Potgieter, G. M., Largier, J. F., Mears, G. E. F. \& Joubert, F. J. (1964), Biochim. Biophys. Acta 82,

463-475.
17. Chesebro, B. \& Svehag, S. E. (1968), Clin. Chim. Acta 20, $527-529$.

18. Zweens, J., Frankena, Henny \& Zijlstra, W. G. (1978), Pflügers Arch. 376, 131-138.
For reprint reguests:

Prof. Dr. W. G. Zijlstra

Department of Physiology

University of Groningen

Bloemsingel 10

NL-9712 KZ Groningen 